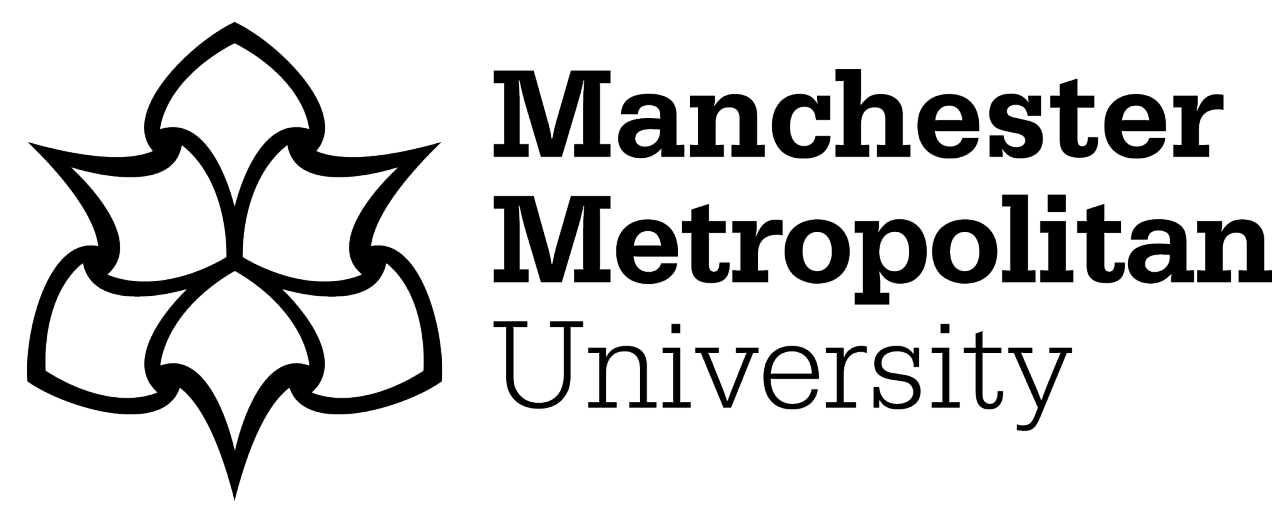

tom Dieck, MC ORCID logoORCID: https://orcid.org/0000-0002-8765-8969 and Jung, Timothy ORCID logoORCID: https://orcid.org/0000-0002-85946641 (2017) Value of augmented reality at cultural heritage sites: A stakeholder approach. Journal of Destination Marketing and Management, 6 (2). pp. 110-117. ISSN 2212-571X

Downloaded from: https://e-space.mmu.ac.uk/618170/

Version: Accepted Version

Publisher: Elsevier

DOI: https://doi.org/10.1016/j.jdmm.2017.03.002

Usage rights: Creative Commons: Attribution-Noncommercial-No Derivative Works 4.0

Please cite the published version 
This is the authors' final version of an article published in Journal of Destination Marketing \& Management

The original publication is available at: DOI:10.1016/j.jdmm.2017.03.002

Journal of Destination Marketing \& Management

Research Paper: Value of Augmented Reality at Cultural Heritage Sites: A Stakeholder Approach

M. Claudia tom Dieck ${ }^{\mathrm{a}}$ and Timothy Jung* ${ }^{\mathrm{a}}$

${ }^{a}$ Faculty of Business and Law, Manchester Metropolitan University, Righton Building, Cavendish Street, Manchester M15 6BG, UK

ABSTRACT:

As the pace of Augmented Reality (AR) adoption quickens, cultural heritage sites have begun to focus on the opportunities provided by this new and innovative technology. However, small organizations often fear making large investments in AR without a proof of concept due to the risk of failure. Therefore, it is imperative to explore the perceived value of AR from multiple stakeholders' perspectives to ensure the long-term viability of technological innovations in small cultural heritage organizations. The present study uses a small museum in the UK to explore the perceived value of the implementation of AR within the museum context using a stakeholder approach. Qualitative data were gathered from twenty-four stakeholders via focus groups and interviews. This case study shows that AR has economic, experiential, social, epistemic, cultural \& historical, and educational value from both internal and external stakeholders' perspectives. AR is considered to be a way to preserve history, enhance visitor satisfaction, generate positive word-of-mouth, attract new target markets and contribute to a positive learning experience. This paper contributes to the knowledge gap in the area of stakeholders' perceived value of AR for cultural heritage tourism.

Keywords: Augmented reality, Perceived value, Cultural heritage sites, Visitor experience, Stakeholder approach

PLEASE CITE THIS ARTICLE AS:

Tom Dieck, MC., Jung, T.H. (2017). Value of Augmented Reality at Cultural Heritage Sites: A Stakeholder Approach, Journal of Destination Marketing \& Management. (ISSN: 2212-571X) DOI:10.1016/j.jdmm.2017.03.002 


\section{Value of Augmented Reality at Cultural Heritage Sites: A Stakeholder Approach}

\section{Introduction}

The pace of Augmented Reality (AR) adoption in the tourism sector is increasing. While Yovcheva et al. (2012) were one of the first researchers to identify the potential of overlaying digital content onto tourists' real environment, nowadays many destinations and organizations have either implemented or begun to consider the opportunities offered by this new and innovative technology to enhance the visitor experience. The last few years have seen a large number of scholars conducting research on AR user requirements (tom Dieck et al., 2016), AR acceptance and behavioral intentions (Jung et al., 2015b; Rauschnabel \& Ro, 2016; tom Dieck and Jung, 2015), the creation of an AR tourism experience (Han et al., 2017), as well as AR tourism gaming (Linaza et al., 2013). Although larger destinations and organizations have been able to implement mobile AR applications to test opportunities for visitor engagement, smaller organizations with limited resources need to carefully examine the potential benefits before investing resources in AR. Chesher and Skok (2000) revealed that many smaller organizations fear that the costs of investing in these technologies do not outweigh the benefits received afterwards. Therefore, the identification of AR's perceived value to stakeholders is a necessary first step prior to investment and implementation.

Taebi et al. (2014) noted that technological innovations are made within a specific context, and a broad range of stakeholders should be involved in the planning process to evaluate their potential value before they are implemented. McCabe et al. (2012) supported the need for research on digital technology for the tourism experience by using a stakeholder approach. Business literature has long found value creation to be directly linked to long-term profitability and business success (Peppard \& Ward, 2016). There are a number of perspectives on perceived value. Gordon et al. (2015) theorized perceived value into subcategories of ecological, social, emotional, economic and functional value. Jiang and Kim (2015) recently added epistemic value as one of the perceived value perspectives within their latest theoretical model. Within the cultural heritage tourism context, Chiabai et al. (2013) identified environmental, emotional, historical, cultural, tourist and social value as important kinds of value.

All these value dimensions provide important implications for how information systems are delivered and accepted (Baird \& Raghu, 2015). However, research on the perceived value of AR applications within the cultural heritage tourism context is limited. Particularly small cultural heritage organizations have to ensure that the benefits expected by stakeholders are delivered when implementing AR, due to the high costs involved (Chesher and Skok, 2000). Furthermore, Lee et al. (2013) revealed that the majority of research concerning technological developments to date focused solely on customer orientation and market orientation in large companies. Therefore, the present study uses the case study of a small museum in the UK to examine the perceived value of AR applications within the museum context using a stakeholder approach. 


\section{Literature Review}

\subsection{Augmented Reality in Cultural Heritage Tourism}

AR is the digital overlay of information on users' immediate surroundings, using devices such as mobile phones or head mounted displays (HMD), and smart glasses in particular (Rauschnabel et al., 2015). Over the past few years, the advancement in sensor technologies has led to increased availability and use within the tourism sector (van Krevelen and Poelman 2010). Developed in 1968, AR has been applied to many industry sectors (Jung et al., 2013). More recently, the tourism sector has begun to understand the opportunities for overlaying digital content onto tourists' real environment (Jung et al., 2015a). Navigation functions and the potential to overlay content without disturbing the real environment are just some advantages that make AR so attractive to the tourism industry (van Krevelen \& Poelman, 2010). Likewise, it allows historical buildings to be brought back to life through re-enactments of old events and explanations of their meaning (Gervautz \& Schmalstieg, 2012). Advancements in technology, moving from marker-based to marker-less overlays, have made AR even more suitable for the tourism context, as tourists can retrieve context-based content using GPS. In addition, enhanced image recognition allows tourists to scan buildings and objects and receive content without designated QR codes (Wang et al., 2013). These technological developments have made the tourist AR experience more user-friendly and efficient, and are thought to contribute to the overall acceptance of these applications (tom Dieck and Jung, 2015).

Previous research clearly shows the potential of AR to create an interactive and enjoyable tourism experience (tom Dieck et al., 2015) while in the museum context, AR adds another element of learning (Moorhouse et al., 2017; Yoon et al., 2012). As the ability to learn is dependent on learners' collaborative participation in the learning process, interactive features of AR applications can facilitate active learning (Dunleavy and Dede, 2014). Telling hidden stories and enhanced content are some ways museums use AR to enhance the visitor experience (Leue et al., 2015). In addition, Jung et al. (2015b) conducted a study on cultural differences in AR in heritage sites and found that Western visitors have a strong desire to escape reality through AR applications. Therefore, museums and art galleries in Western culture have to focus more on the creation of an immersive and enjoyable experience compared to those in Eastern cultures, which have a stronger focus on education. Studies in the area of tourism and museum AR have mostly focused on combining tourism products with AR functions (Noh et al. 2009; Marimon et al. 2010). However, research with regards to the potential of AR and its perceived value to museum stakeholders is still limited.

\subsection{Value Creation through IT}

Value creation has been thoroughly discussed in business strategy literature and is generally considered the key to long-term profitability and business success (Peppard \& Ward, 2016). In principal, delivering high value affects customer satisfaction and loyalty, which in turn influences business success; thus, value creation is considered immensely important for profitable business operations (McDougall \& Levesque, 2000). However, as the term implies, perceived value is subjective, and organizations' internal stakeholders may have different opinions than customers (Eggert \& Ulaga, 2002). Melville et al. (2004) proposed a business value model based on the Resource Based View (RBV) and revealed that organizations should focus their IT strategies on internal and available resources rather than on a trend in the external market. In particular, it was revealed that resources should not only be linked to financial assets but to expertise, skills and experiences within the workforce (Ward \& Daniel, 2006).

According to Farbey et al. (1993), organizational value as delivered by IT can be divided into strategic, management, operational and functional/support value. Farbey et al. (1993) 
categorized organizational value according to Mintzberg's (1983) view of the structure of an organization. This structure was based on the empirical study of IT project evaluations in 16 organizations from various industry sectors. Furthermore, Ward and Daniel (2006) extended the concept of generic benefits of IT from the perspective of value management. Applying organization-wide value through IT in the context of cultural heritage tourism, strategic value should: support organization's vision and strategies; be viable in the short and long term,; provide visitors with unique value propositions; be innovative; and provide opportunities for new business models. Management value encompasses the enhanced skills of employees and consequent ease of operations (Ward \& Daniel, 2006). In addition, new IT systems were found to make existing systems inadequate, which was also found to be of value for management (Farbey et al., 1994). Operational value includes the reduction of costs, enhanced turnaround time and increased income from better quality products and services (Ahire, 1996). Functional and support value includes employee self-service and improved communication opportunities. However, as noted by Brown (2005), these value factors largely differ from case to case. Therefore, it is essential to evaluate opinions from different stakeholders to ascertain that value is achieved. Nevertheless, in particular, research is required to investigate the association of consumers' perceived value with innovative digital services such as AR. Such relationships need to be considered to create business models that reflect the significant impact of consumer value on the delivery of information systems (Baird \& Raghu, 2015).

Perceived value spreads across several dimensions including ecological, social, emotional, economic and functional value (Gordon et al., 2015; Koller et al., 2011). Jiang and Kim (2015) added epistemic value in the context of Korean hotels. According to Sanchez-Fernandez and Iniesta-Bonillo (2007, p. 437), 'epistemic value is concerned with a desire for knowledge, whether this be motivated by intellectual curiosity or the seeking of novelty'. This idea is closely linked to integrating AR into the museum experience to create a new, interactive way of experiencing history. Interestingly, Kim et al. (2011) considered the experience economy as part of the value creation framework and classified functional, emotional and epistemic value as part of experiential value. A holistic definition was provided by Wu and Liang (2007, p. 588) who defined experiential value as the 'value [that] is derived from how a product creates appropriate experiences, feelings and emotions in a customer'.

The importance of perceived value was also addressed within the cultural heritage tourism context. Chiabai et al. (2013) used a stakeholder approach to explore how innovative information communication technology (ICT) tools can be used to enhance cultural heritage sites. Their findings revealed six categories of perceived value including environmental, emotional, historical, cultural, tourist and social. In addition, Chiabai et al. (2013) found differences in the importance of each value between different stakeholders. This strengthens the need to incorporate a variety of stakeholders' opinions when developing technologies to ensure that all concerns are addressed (Hall \& Martin, 2005). Furthermore, vom Lehn and Heath (2005) explored the value of new technologies for the museum experience and found that they can add economic value by increasing visitor numbers. Their research observed that new technology delivered social value by facilitating co-participation in the museum experience, and increased the amount of time visitors spent in an exhibition (vom Lehn \& Heath, 2005). This example from the museum sector shows that technology can offer various kinds of value that need to be examined in more detail. As can be clearly seen from the reviewed literature, there are numerous dimensions of perceived value; however, context-specific value constructs from the perspective of multiple stakeholders need to be explored prior to technology investment and implementation. Based on the reviewed literature, the present study aims to 
explore stakeholders' perceived value regarding the implementation of AR with the aim of enhancing the museum experience.

\subsection{Stakeholder approach}

Originally developed by Freeman (1984), the stakeholder approach suggests that a company's stakeholders can be classified as internal (employees, managers, owners) and external (suppliers, society, government, creditors, shareholders, customers). As per the stakeholder approach, business success can ultimately be measured by the extent to which all parties are served better by the business in question than by the competition (Nickols, 2005). According to Freeman (2004), since the early 1980s, the interest in applying a stakeholder approach to research has grown tremendously, leading to the popularity of the stakeholder approach to answer a wide array of research questions. As defined by Sautter and Leisen (1999, p. 313), a stakeholder 'is any group or individual who can affect or is affected by the achievement of the organization's objectives'. Within the field of Research and Development, the involvement of multiple stakeholders was shown to enhance the value and improve the effectiveness of implementing new innovations (Tipping et al., 1995).

For instance, Hall and Martin (2005, p. 281) revealed the importance of using a stakeholder approach when researching new and disruptive technologies to 'address the concerns of a wide range of stakeholders'. Kamal et al. (2011) explored the role of stakeholders in UK governments for the adoption of technology. They found that previous research only looked into the adoption from specific stakeholders' point of view, rather than gathering a holistic picture from internal and external stakeholders (Kamal et al., 2011). Therefore, it was suggested that future research should conduct a stakeholder analysis for IT adoption by first selecting relevant stakeholders, then investigating stakeholders' perception with regards to IT adoption, and finally ensuring stakeholder involvement in implementation stage (Kamal et al., 2011). Earlier, Douthwaite et al. (2001) confirmed that stakeholders who stand to benefit or suffer as a result of technology integration need to be included in the adoption process. Businesses therefore have to create a stakeholder map in order to identify each individual or group with a stake in the company. According to Yuksel et al. (1999, p. 354), the inclusion of individuals or groups as stakeholders depends on their 'legitimate interest'. Mitchell et al. (1997, p. 864) emphasized that no stakeholder theory can provide definite answers to who should be considered a stakeholder; however, the attributes of power, urgency and legitimacy are widely acknowledged to be part of the 'stakeholder-manager relationship'. Buchholz and Rosenthal (2005) added that those groups or individuals who could potentially gain or lose as the result of a decision should be included in a stakeholder map. The importance of including multiple stakeholders in IT decision making was confirmed by Li (2007) in the education sector. His findings revealed that students (consumers) had a much more positive attitude towards the integration of IT compared to teachers (suppliers), who considered IT to be a time-consuming process and not at all relevant to achieving learning outcomes. This shows clearly that time efficiency could be an incentive for teachers to adopt technologies, while students sought effective, efficient and fun applications ( $\mathrm{Li}, 2007)$. The importance of stakeholder theory becomes apparent when considering that the goals of each individual or group of stakeholders must be considered in order to understand how to satisfy their values ( $\mathrm{Li}, 2007)$.

Tourism research has long understood the importance of stakeholder collaboration to the enhancement of the tourism experience (Kourtit et al., 2014; McCabe et al., 2012). Stakeholders of museums are defined 'as groups and actors that influence or depend on the decisions of museums [and] include owners, governments, grant givers, visitors/customers, the general public, donors, friend associations, sponsors, and providers of services and goods used by the 
museum' (Lindqvist, 2012, p. 8). Particularly for the development of new exhibitions and introduction of new technologies, it is essential to involve a number of stakeholders (Hall \& Bannon, 2006). This ensures that all parties involved are part of the co-creation process. In addition, McCabe et al. (2012) revealed that the use of a stakeholder approach for the implementation of innovative technologies helps to overcome knowledge barriers, as a wide range of opinions is taken into consideration prior to development. This was confirmed by an earlier study which found "early key stakeholder participation reduces the risk of the development of inappropriate technology and is more parsimonious because the key stakeholders embody the necessary local knowledge themselves [and] key stakeholder participation increases the potential sources of innovation and so increases ... the fitness of the technology' (Douthwaite et al., 2001, p. 834). Especially in the tourism context, McCabe et al. (2012) showed that the inclusion of tourists' point-of-view is essential to ensure a strong focus on creative tourist experiences through IT. Therefore, it is essential to incorporate the view of all stakeholders involved to explore the perceived value of AR within the small museum context. In fact, Lee et al. (2013, p. 214) revealed that 'small firms that can deliver the appropriate match between the required technology-oriented activities, technology adoption, and utilizations are the ones that are likely to survive and thrive'.

\section{Methods}

This exploratory study focuses on a small museum in the UK with 15,000 visitors a year, including 10,000 school children. The museum experience currently does not involve technology, and the displays and historical context are explained by tour guides or paper plaques. As part of a future expansion, the museum aims to explore the potential implementation of AR to enhance the museum experience.

This study explored the views of museum stakeholders regarding the perceived value of AR; therefore, a first step was to identify relevant stakeholders. From a review of literature (Kelly, 2006; Sautter \& Leisen, 1999) and discussion with museum personnel, the following stakeholders were identified as stakeholders of the museum in the context of creating an AR experience: Individuals (CEO, manager, community representatives, trustees and local council office managers); groups (volunteers, schools, visitors). According to Li (2007, p. 378), 'stakeholder groups interact with each other and carry out certain tasks that enable the environment [museum] to function'. Therefore, it is difficult to generalize the number and specific nature of stakeholders. Within the context of the current study, school teachers were considered important external stakeholders due to the museums' $2 / 3$ target market of school groups. In addition, community representatives and the local council were suggested as stakeholders by museum personnel due to the museum's desire to attract more residents into the museum, concurring with previous research by Kelly in 2006 .

Qualitative data were gathered from twenty-four stakeholders via focus groups and interviews between July 2015 and March 2016, and theoretical sampling was used to identify the most important informants for interviews. Stakeholder interviews (museums' CEO, manager, volunteers, school teachers, trustees, community representatives, local council office managers) and two visitor focus groups (young/senior) were conducted. As shown in Table 1, the first interviews were conducted in July 2015. As suggested by Mayers (2005) as part of the stakeholder power analysis, during these interviews participants were asked to suggest further stakeholders with an interest in the potential of AR for the museum. Interviews with these additional stakeholders were then conducted in February/March 2016. To conclude, the sample was selected to get a fair representation of stakeholders' opinions, internally and externally, about the perceived value of AR for the museum. 
The justification for conducting focus groups with visitors is that the museum attracts groups rather than individuals; also, considering their tight museum visit schedule, the tour groups were only able to accommodate giving feedback as a group. In addition, a reason to conduct focus groups for the visitor groups was to gather different opinions; due to the novelty factor of AR, it was hoped that visitors would feel more open to discussing possibilities for new technologies in a group. On the other hand, museum staff and teachers were expected to provide in-depth information and thus interviews were perceived as the most appropriate datacollection method. Interviews lasted between 13 to 29 minutes, while focus groups lasted between 28 to 55 minutes.

Prior to the interviews/focus groups, participants were provided with an explanation of AR as well as a short video demonstrating AR in the museum environment. However, they did not experience an AR application in the museum. Interview and focus group questions were designed using a theoretical interest approach (Corbin and Strauss, 2015). The semi-structured questions inquired about prior AR experience, perceived value of AR, suitability for target markets, potential of enhancement of visitor experience through AR, and essential content required for the museum AR application. The interviews were analyzed for themes and subthemes on perceived value aiming to address the theoretical interest of this paper as guided by the literature review on perceived value (Vogt et al., 2016).

According to Boyatzis (1998), the use of thematic analysis allows the researcher to form themes prior to the analysis, allowing sub-themes to emerge during the process of analyzing data. Prayag and Ryan (2011), who found that thematic analysis requires the researcher to thoroughly review the literature and collect relevant data for different codes, support this process. The researchers developed codes based on the value dimensions identified within previous literature. For example, the researchers identified economic value (Gordon et al., 2015; Koller et al., 2011) and epistemic value (Jiang \& Kim, 2015) as relevant themes. The next step included the revision of literature to identify appropriate sub-themes such as increased sales, profit maximization etc. in order to generate a thematic map (Boyatzis 1998). Then the researchers analyzed the interview transcripts in order to identify existing themes and subthemes as well as to generate emerging themes and sub-themes (Prayag and Ryan, 2011). 


\begin{tabular}{|c|c|c|c|c|c|}
\hline Abbreviation & Participant & Gender & Age & Mode & Interview \\
\hline $\mathrm{CEO}$ & Chief Executive Office & Male & $30-39$ & Interview & July 2015 \\
\hline CR1 & Community Representative & Male & 60 and above & Interview & Feb 2016 \\
\hline CR2 & Community Representative & Male & $30-39$ & Interview & Feb 2016 \\
\hline $\mathrm{LC}$ & Local Council & Female & $30-39$ & Interview & Mar 2016 \\
\hline $\mathrm{OM}$ & Office Manager & Female & $30-39$ & Interview & July 2015 \\
\hline SV1 & Senior Visitor 1 & Female & 60 and above & FG & July 2015 \\
\hline SV2 & Senior Visitor 2 & Male & 60 and above & FG & July 2015 \\
\hline SV3 & Senior Visitor 3 & Male & 60 and above & FG & July 2015 \\
\hline SV4 & Senior Visitor 4 & Female & 60 and above & FG & July 2015 \\
\hline SV5 & Senior Visitor 5 & Female & 60 and above & FG & July 2015 \\
\hline TR1 & Trustee & Female & $40-49$ & Interview & Feb 2016 \\
\hline TR2 & Trustee & Male & $30-39$ & Interview & Feb 2016 \\
\hline $\mathrm{T} 1$ & Teacher 1 & Female & $40-49$ & Interview & July 2015 \\
\hline $\mathrm{T} 2$ & Teacher 2 & Female & $50-59$ & Interview & July 2015 \\
\hline T3 & Teacher 3 & Female & $20-29$ & Interview & July 2015 \\
\hline $\mathrm{T} 4$ & Teacher 4 & Male & $40-49$ & Interview & July 2015 \\
\hline T5 & Teacher 5 & Male & $30-39$ & Interview & Feb 2016 \\
\hline V1 & Volunteer 1 & Female & 60 and above & Interview & July 2015 \\
\hline $\mathrm{V} 2$ & Volunteer 2 & Male & 60 and above & Interview & July 2015 \\
\hline V3 & Volunteer 3 & Female & 60 and above & Interview & July 2015 \\
\hline V4 & Volunteer 4 & Male & $50-59$ & Interview & July 2015 \\
\hline YV1 & Younger Visitor 1 & Male & $20-29$ & FG & July 2015 \\
\hline YV2 & Younger Visitor 2 & Male & $30-39$ & $\mathrm{FG}$ & July 2015 \\
\hline YV3 & Younger Visitor 3 & Female & $30-39$ & FG & Julv 2015 \\
\hline
\end{tabular}

Table 1. Stakeholders' Profile

\section{Findings}

Findings show that there are numerous perceived value dimensions of AR within the cultural heritage tourism context for stakeholders, including economic, experiential, social, epistemic, historical \& cultural and educational value. A summary of themes, sub-themes and stakeholders who mentioned each sub-theme is presented in Table 2. This shows the associations between roles held by stakeholders and their perceptions of the value regarding the future adoption, implementation and investment of AR technology in small museums. In addition, the findings discuss the value from an internal organization-wide perspective and external stakeholders' perspective.

\begin{tabular}{|c|c|c|}
\hline Value of AR & Sub-themes & Stakeholders \\
\hline \multirow[t]{7}{*}{ Economic } & - Attracting new target markets & Internal (OM) \\
\hline & — Increased footfall numbers via enhanced & Internal (CEO, OM, V1-4, TR1-2)/ \\
\hline & visitor engagement & External (CR1) \\
\hline & - Justification to charge for admission & Internal (OM) \\
\hline & — Increased sales & Internal (TR2) \\
\hline & - Incentives to return & External (Visitors) \\
\hline & - Fundraising through link to community & External (CR1) \\
\hline \multirow{4}{*}{ Experiential } & — Interesting and exciting experience & Internal (CEO)/All external stakeholders \\
\hline & - Interactive and enjoyable experience & Internal (OM, Volunteers)/ All external \\
\hline & - Enriching memories & External stakeholders $(\mathrm{T})$ \\
\hline & $\begin{array}{l}\text { - Bringing history to life to enhance emotional } \\
\text { attachment }\end{array}$ & All stakeholders \\
\hline \multirow{4}{*}{ Social } & - Gamification to enhance social interaction & External (T5, YV1-3) \\
\hline & $\begin{array}{l}\text { - Sharing experience online through social } \\
\text { media }\end{array}$ & External (YV1-3) \\
\hline & - Sharing scores among peers & External (T5) \\
\hline & - Social fulfilment & External (all Teachers) \\
\hline
\end{tabular}




\begin{tabular}{|c|c|}
\hline Epistemic & $\begin{array}{l}\text { - New concept for engagement } \\
\text { - Increased attention when using an alternative } \\
\text { approach to visiting museums } \\
\text { - Enhanced experience via new technologies } \\
\text { - Exploring exhibitions in a new light } \\
\text { - Curiosity of trying new technologies }\end{array}$ \\
\hline $\begin{array}{l}\text { Historical and } \\
\text { Cultural }\end{array}$ & $\begin{array}{l}\text { - Showcasing the museum as it used to be } \\
\text { - Adding more content to exhibition to bring } \\
\text { history to life } \\
\text { - Telling personal stories of past events } \\
\text { - Trigger interest in history } \\
\text { - Creating a virtual part of the museum }\end{array}$ \\
\hline Educational & $\begin{array}{l}\text { - Translations of ancient content } \\
\text { - Personalized learning experience } \\
\text { - Learning at own pace } \\
\text { - Enjoyable and interactive learning } \\
\text { experience } \\
\text { - Saving content for later } \\
\text { - Easier to memorize information } \\
\text { - Less experienced staff could utilize the } \\
\text { application to learn about the experience }\end{array}$ \\
\hline
\end{tabular}

All except CEO, OM, TR1-2, YV1-3

External (T1)

External (all Teachers)

External (all SVs)

External (SV3)

Internal (CEO, OM)

Internal (CEO, OM, TR)

External (YV1-3)

External (all Teachers)

Internal (TR2)

External (all SVs)

Internal (V2)/ All external

External (all visitors)

External (all SVs)

External (all SVs)

External (all SVs, all Teachers)

Internal (V1)

Table 2. Perceived Value Constructs for AR in the Cultural Heritage Tourism Context 


\subsection{Value of ICTs at Small Cultural Heritage Sites}

There has been general recognition of the value of ICTs at cultural heritage sites. From an organizational perspective, CEOs, OMs and trustees revealed that ICT aids in the acquisition of new target markets. The importance of strategic thinking and development of visions were discussed in the literature as strategic value created from within an organization. According to the CEO of the small museum explored in this case study, 'the key strategy is to start engaging with more audiences, to make the museum more engaging and relevant to a much broader range of audiences using technologies'. This shows that the use of ICTs is clearly part of a future strategy within the museum. This approach is supported by teachers who suggested that the use of ICTs makes the museum a more vibrant learning environment for school children. T3 strengthened 'using technology, that really does hook our children, like iPads, they enjoy and it makes it more engaging [...] by engaging I mean it enhances their attention span, it really does interest them'. Young and older visitors alike agreed that the small museum could benefit from integrating some technology into the museum experience in order to bring the museum more to life, attract younger audiences and enhance engagement. The small museum in this case study concurred with this point-of-view and therefore showed an interest in the potential of AR's overlay of digital content into visitors' direct surroundings: 'I think I want to use it because [...], I think it will enhance the visitor experience [...], we really want our museum to be active and different and interesting' (OM). The importance of being an innovative and forward-thinking organization can be considered a key strategic value. Currently, the museum does not offer any technologies to its visitors and thus, the investigation into the potential value of AR was perceived as an important stepping-stone, to ensure value to both internal and external stakeholders.

\subsection{Value of AR at Small Cultural Heritage Sites \\ 4.2.1 Economic Value}

Economic value relates to the costs involved and whether services or products are worth investing in (Jiang \& Kim, 2015). This particular value dimension was considered to be enormously important from the small organizational point-of-view. A number of internal stakeholders revealed that the museum needs a fresh approach to visitor engagement to ensure increased visitor numbers (CEO, OM, V1-4, CR1, TR1-2). Also, the community representative (CR) revealed that new technologies have to be financially viable. From the museum's strategic value point of view, this is an important value construct, as the identification of new business models was revealed to be an important step towards competitiveness. It was identified that particularly small museums, which rely on admissions, have to offer an enjoyable experience to ensure high satisfaction rates and positive word-of-mouth, and in turn attract new target markets (OM). However, it was furthermore confirmed that there needs to be an 'upgrade of the facilities' (TR1) and 'if you are offering a better visitor experience then you have got the justification' to charge for admission (OM). From the operational value point of view, it is important to ensure income can be generated from an enhanced visitor experience. Considering the importance of strong visitor numbers for the sustainability of museums, the right approach to visitor engagement through the implementation of technologies was perceived as a key success factor for economic value (TR1-2, CR1). The senior visitor group agreed that they would be prepared to pay an extra fee if interactive experiences should be available. Again, visitors confirmed the importance of $\mathrm{AR}$ for operational value, as they agreed it could generate increased income. As discussed previously, school classes are an important generator of income as they are considered the main target market, and all five teachers confirmed that they would be more likely to return if an interactive application was available. Similarly, visitors agreed that enhanced information and interpretation through AR would be an incentive to return in the future as well as spread positive word-of-mouth. Although visitors discussed their intention to 
return as a result of AR, they did not specifically pick up on any financial implications for the small museum, thus strengthening the importance of economic value mostly from the organizational point-of-view. TR2 raised the idea that AR could be used for upselling (e.g. charging a fee for headphones or the renting of devices). However, he strongly suggested that the download and use of an AR application should be part of the existing admission fee (TR2). Another economic value was identified with regards to the idea of fundraising. Small museums are often dependent on donations to survive on the market. AR is considered an ideal tool to tell personal stories, and linking those stories of community groups to the museum experience could persuade these groups to become beneficiaries of the museum (CR1) which supports TR1's opinion that all ideas need to be financially viable to be implemented in the long term.

\subsubsection{Experiential Value}

According to Yuan and Wu (2008, p. 391), 'experiential value refers to customers' perceptions of products or services through direct use or indirect observation'. The theme of experiential value emerged throughout interviews with internal and external stakeholders. Considering management value, the museum is currently perceived as a cultural experience, which requires volunteers to create an interactive and enjoyable visitor experience $(\mathrm{OM})$. In the future, $\mathrm{AR}$ could be utilized to decrease the number of tour guides required due to personalized digital tours. This would add to the overall managerial value discussed in literature. According to two teachers (external stakeholders), school children provide mixed signals with regards to the current experience as some find it 'boring as they don't like to read a lot of the information' (T3). Internal stakeholders agreed with this problem and currently try to formulate strategies to make the experience 'more interesting, more exciting' (CEO). Another teacher (T1) confirmed, 'it would improve their memories and their enjoyment of going to visit'. This increased enjoyment through AR was confirmed by a range of stakeholders, from seniors and younger visitors to volunteers and community representatives. In general, museum experiences can be very static, and all stakeholders, internally and externally, agreed that AR could bring stories to life, resulting in more fulfilling and enjoyable experiences. In addition, experiential value is expected to be enhanced when technology is added to the experience, enabling personal stories to be told.

\subsubsection{Social Value}

Social values connect to customers' and businesses' public recognition that services or product lead to personal fulfilment and impression making (Gordon et al., 2015). The theme of social value was only brought up by external stakeholders such as teachers and visitor groups. In fact, the young visitor focus group (YV1-3) thoroughly discussed the idea of gamification and how interactive games could enhance the social aspect of the museum visit. Treasure hunts could take place, whereby visitors are required to explore certain areas of the museum, take part in quizzes and simply test their learning outcomes. An AR app could allow visitors to share their scores on treasure hunts or quizzes on social media, leading to a sense of personal fulfilment and sharing their experience with friends and family. According to T5, this is also an important aspect for pupils. Children tend to pay more attention if they know that their knowledge about the exhibitions will be tested at the end of the visit. Hence, if AR apps allow for the comparison of scores between peers, children could tend to have a stronger motivation to actively participate in the museum visit. Consequently, social fulfilment seems to play an important role from the external stakeholders' point-of-view. Considering that internal stakeholders did not acknowledge the importance of social value, this seems to be an important issue that should be implemented in future ICTs investments in order to ensure external stakeholders' satisfaction. Ultimately, internal stakeholders perceived economic value as immensely important, and thus 
should ensure that social aspects are taken into account to ensure positive word-of-mouth, recommendations and visitors' intentions to return.

\subsubsection{Epistemic Value}

Epistemic value is an important concept linked to consumers' curiosity about new products and their willingness to experience something new (Jiang \& Kim, 2015). Similarly to social value, epistemic value was left out by internal stakeholders, but appeared to be an important value dimension for external stakeholders. This may be linked to the novelty factor of AR. The concept of AR was relatively new to most stakeholders (except CEO, OM, TR1-2 and younger visitors). Consequently, there was strong interest in the potential of AR for the enhancement of the experience. Teachers in particular identified that the availability of latest technologies would improve the experience of school children, as they tend to pay more attention if they are using novel ways of learning. T1 stated with regards to school children, 'it would just enhance their fun of coming out to museums'. Interestingly, the senior visitor group also showed a strong interest in the concept of AR and the potential to explore the museum in a new light; however, they acknowledged that a good personal guide could create a very enjoyable experience (SV3) and that younger audiences were more curious to try new technologies.

\subsubsection{Cultural and Historical Value}

There has been a general recognition that AR would enhance cultural and historical value through the provision of additional information for all age groups. The museum in question was once a synagogue. A number of internal stakeholders confirmed that synagogues were spaces of gathering; however, the transformation into a museum has made it a quiet place (CEO, OM, V3). Thus, AR is hoped to bring the historic building back to life. As discussed previously, one of the management values of IT is the overhauling of existing systems that may become inadequate or obsolete due to changes. The findings of this study support this value construct and suggest that AR can be used to create changes to the environment and experience. Furthermore, TR2 and CEO revealed another cultural value with regards to extending collections that are impossible to display due to space constraints. Therefore, 'augmented reality could be used to double the space and create a virtual part of the museum' (TR2). Nonetheless, external stakeholders equally recognized cultural and historical value as a result of implementing AR in a small museum. The younger visitors in particular found a number of possibilities for the enhancement of the visitor experience through AR, including story-telling and personalization. In addition, while visitors reckoned that AR will persuade children to visit the museum, teachers welcomed the opportunity to have interactive visits that could trigger pupils' interest in history. Nevertheless, TR2 added that the history has to be treated carefully and a good mix between physical visit and experience and virtual elements should be ensured. History is an important part of today's society and technologies such as AR should ensure that history is told correctly (TR2).

\subsubsection{Educational Value}

The educational value of AR emerged as a construct for the context of museums. There has been a general recognition that AR would enhance the visitor learning/educational experience through the provision of information for all age groups. However, school groups are the main target market of the museum and all stakeholders recognized that AR applications would be wonderful educational additions to the museum experience for the younger audience. At the moment, guided tours are an important part of the museum's experience, and help to tell the stories behind the displays and give personal recollections of the past (V2). According to all participants (SV1-5; YV1-3), AR would allow visitors to gather information by themselves, at their own pace, which was considered a big advantage for a personalized educational 
experience. For instance, SV1 identified that AR could allow visitors to collect as much content as desired, which would provide a more enjoyable and interactive learning experience. SV2 acknowledged, 'that it brings it more to life, and [allows visitors to] explore more details'. Furthermore, less experienced staff could utilize the application to learn about the experience, thus adding managerial value (V1). Finally, translations could aid the learning and understanding of content. The senior visitor group noted that an application would allow visitors to save information and review it after the experience. In addition, reviewing information again would make it easier to memorize the experience and retain new information. Therefore, particularly from visitors' and teachers' points of view, AR is extremely important to educational value.

\section{Discussion and Conclusion}

\subsection{Discussion}

This study aimed to explore stakeholders' perceived value regarding the implementation of AR to enhance the museum experience at cultural heritage sites. In particular, this research used a small museum in the UK as a case study. Across stakeholder interviews and focus groups, there was a common agreement that the implementation of AR adds a number of different aspects of value to the museum and the visitor experience. This supports previous research by Cranmer et al. (2016, p. 639) who found 'AR will attract a different market and in general add-value allowing people to get much more out of their visits'. Within the context of the present study, this value can be categorized into economic, experiential, social, epistemic, cultural \& historical and educational subgroups. These findings support previous research by a number of scholars (e.g. Chiabai et al. 2013; Jiang and Kim, 2015). Nevertheless, themes relating to tourist, ecological, functional or emotional value were not found in this study. However, our findings support previous research by Chiabai et al. (2013) within the cultural heritage context. In addition, the importance of educational value can be linked to the specific case study, a museum that has school children as its main target market. Furthermore, interviews with internal stakeholders found that the synagogue should be brought back to life, and according to Gervautz and Schmalstieg (2012), AR is an ideal technology to re-enact historical events without compromising original architecture and landscapes, which signals the importance of cultural and historical value in this value proposition.

Overall, the findings show that AR is perceived as having strong value, both internally and externally. While external stakeholders mostly identified value to the visitor learning experience, internally AR was perceived to create managerial, strategic and operational value (Ahire, 1996; Farby et al., 1993; Farbey et al., 1994; Ward \& Daniel, 2006). It offers new opportunities for change in the future and allows for a strategic direction that embraces the latest technologies. Considering the strategic value of $\mathrm{AR}$, financial constraints are a big problem for small museums. As identified within this study, AR could be used as an opportunity for fundraising within the local community as well as to justify the charging of admission. Considering the limited revenues that small museums may collect as a result of low visitor numbers, technologies such as AR were found to be an opportunity to overcome economic issues (Gordon et al., 2015; Koller et al., 2011). In addition, socially, AR can help to create a joint experience which may add to positive word-of-mouth, in turn leading to an increase in visitor numbers (Gordon et al., 2015; Jiang \& Kim, 2015).

Having conducted a stakeholder analysis, there is a clear discrepancy between internal and external stakeholders with regards to certain value constructs. For instance, it is clearly visible that economic value is prioritized by internal stakeholders such as the CEO, officer manager and trustees, as small museums are currently under enormous pressure to finance their 
operations (Gordon et al., 2015; Koller et al., 2011). Thus, the latest technologies appear to be part of their strategy to ensure future success. Another interesting finding is internal stakeholders' strong interest in cultural and historical value, showing that AR is considered an ideal tool to help museums bring history and culture to a life (Chiabai et al., 2013; Gervautz \& Schmalstieg, 2012). From the interviews with internal stakeholders it became apparent that financial benefits - created by enhanced visitor experiences, increased visitor numbers and higher intention to return - are considered to be an integral incentive for implementing a new technology such as AR (vom Lehn \& Heath, 2005). External stakeholders, and in particularly teachers, were very much interested in the learning experience, as well as how AR can be used to make their visit more personal, effective and interactive. The epistemic value was hereby considered particularly important since new technologies such as AR can make the experience more exciting. The social value of sharing information and experiences was also perceived to be enormously important by external stakeholders (Chiabai et al., 2013; Gordon et al., 2015; Jiang \& Kim, 2015).

The insight from the current case study from one small museum has broader relevance for attraction management and marketing strategies. For example, other museums could investigate the value of IT and explore which particular technology is most appropriate for implementation, as this study has shown the importance of investigating AR on a case by case basis (Brown, 2005). Overall, research within the museum AR context is still scarce and this is particularly true for exploratory approaches and opinions on the value of AR from various stakeholders. Thus, this study adds to the pool of knowledge in this tourism domain. Previously, a number of studies found AR to have potential for the enhancement of the visitor experience (Jung et al., 2015a; tom Dieck \& Jung, 2015) and stakeholders confirmed these findings within this study.

\subsection{Theoretical contributions and managerial implications}

This study makes a number of theoretical contributions. The field currently lacks explorations of the potential of AR from the internal stakeholder perspective (Cranmer et al., 2016), and therefore, the present study contributed to this limited research by examining the perceived value of AR for the museum context using a stakeholder approach. As shown in the literature review, there are many different value dimensions and research is required within different academic disciplines to support existing constructs and explore context-specific ones. Previous researchers identified numerous different perceived value constructs, and our findings explored six perceived value dimensions that are applicable for the AR cultural heritage tourism context from both internal and external stakeholder perspectives. These six constructs can be used for theory development and tested on a large scale to generalize findings. The present case study is unique as it identifies small, museum-specific AR value constructs including economic, experiential, social, epistemic, cultural \& historical and education value, using a stakeholder approach. Therefore, our identified perceived value constructs should be incorporated as part of future value theory development, especially when implementing AR at cultural heritage sites. Finally, the academic research to date focused mainly on the assessment of IT implementations within large firms (Lee et al., 2013); thus, the findings of this study add to the limited research on IT value in small organizations. In addition, the study explored the value concept from both internal and external stakeholders' point of view. In particular, this study took into consideration strategic management literature and delved into stakeholder theory in terms of the power grid of stakeholders, their roles in AR adoption and investment decisions in small museums.

There are a number of managerial implications of this study. Findings of this case study will 
provide guidance for appropriate AR investment decisions in small cultural organizations. Small museums often fear the costs involved in implementing new technologies and the findings of the present study take all key stakeholders' perceived value of AR into account to provide museums with an informed investment decision. From the perspective of RBV (Melville et al., 2004; Ward \& Daniel, 2006), cultural heritage organizations need to have appropriate internal resources with regards to people, technology and finances as part of a business value generation process. This will contribute to better organizational processes and museum experiences. However, external stakeholders often have different ideas about perceived value; therefore it is immensely important to incorporate external stakeholders' point of view (Eggert \& Ulaga, 2002). Overall, identification of perceived value by stakeholders will reduce the perceived risk of high investments and failures, especially for small cultural organizations. In addition, this stakeholder approach will contribute to the long-term sustainability of cultural organizations and their community, as well as profitability. Application design also needs to be carefully planned and prepared to ensure that all stakeholders' expected benefits are incorporated. Therefore, museum professionals and application developers can benefits from the findings of this paper, as it informs the effective design of user interface and user experience for AR applications at cultural heritage organizations.

\subsection{Limitations and future research}

Ecological value was not identified as a theme from the interviews or focus groups within this case study however, research on ICTs and sustainability has been growing over the last few years and clearly shows that technologies can be used to create ecological value within the destination context (Ali \& Frew, 2014). Therefore, future research is recommended to identify whether AR provides ecological value in different study contexts. Furthermore, the use of a stakeholder approach limits the findings to the specific case under investigation. In the future, research is advised to focus on other organizations, visitor attractions or destinations to examine the perceived value of AR. The present study revealed six value constructs within the small museum AR context and future research should test these constructs quantitatively using a structural model to generalize these findings to a wider context.

\section{References}

Ali, A., \& Frew, A. (2014). ICT and sustainable tourism development: an innovative perspective. Journal of Hospitality and Tourism Technology, 5(1), 2-16.

Ahire, S. L. (1996). An empirical investigation of quality management in small firms. Production and Inventory Management Journal, 37(2), 44.

Baird, A., \& Raghu, T. S. (2015). Associating consumer perceived value with business models for digital services. European Journal of Information Systems, 24(1), 4-22.

Brown, A. (2005). IS evaluation in practice. The Electronic Journal Information Systems Evaluation, 8(3), 169-178.

Boyatzis, R. (1998), Thematic analysis and code development-transforming qualitative information. Thousand Oaks, California: Sage.

Buchholz, R.A., \& Rosenthal, S.B. (2005). Toward a contemporary conceptual framework for stakeholder theory. Journal of Business Ethics, 58, 137-148.

Chesher, M., \& Skok, W. (2000). Roadmap for successful information technology transfer for small businesses. Paper presented at ACM SIGCPR conference on Computer personnel research, 6-8 July 2000, Chicago.

Chiabai, A., Paskaleva, K., \& Lombardi, P. (2013). e-Participation model for sustainable cultural tourism management: a bottom-up approach. International Journal of Tourism Research, 15(1), 35-51. 
Corbin, J.M., \& A.L. Strauss (2015). Basics of qualitative research: Techniques and procedures for developing grounded theory. $\left(4^{\text {th }} \mathrm{ed}\right)$. Los Angeles: Sage.

Cranmer, E., Jung, T., tom Dieck, M. C., \& Miller, A. (2016). Understanding the acceptance of augmented reality at an organisational level: the case of geevor tin mine museum. In A. Inversini, and Schegg, R. (Eds), Information and communication technologies in tourism 2016 (pp. 637-650), Heidelberg: Springer International Publishing.

Douthwaite, B., Keatinge, J. D. H., \& Park, J. R. (2001). Why promising technologies fail: the neglected role of user innovation during adoption. Research policy, 30(5), 819-836.

Dunleavy, M., \& Dede, C. (2014). Augmented reality teaching and learning. In M. Merrill, J. Elen, and M. Bishop (Eds.), Handbook of research on educational communications and technology (pp. 735-745), New York: Springer.

Eggert, A., \& Ulaga, W. (2002). Customer perceived value: a substitute for satisfaction in business markets?. Journal of Business \& industrial marketing, 17(2/3), 107-118.

Everett, S., \& Aitchison, C. (2008). The role of food tourism in sustaining regional identity: A case study of Cornwall, South West England. Journal of sustainable tourism, 16(2), 150167.

Farbey B., Land, F., \& Targett, D. (1993). How to assess your IT investment' management today. Oxford: Butterworth Heinemann.

Farbey, B., Targett, D., \& Land, F. (1994). The great IT benefit hunt. European Management Journal, 12(3), 270-279.

Freeman, R. E. (1984). Strategic management: a stakeholder approach. Boston: Pitman.

Freeman, R. E. (2004). The stakeholder approach revisited. Zeitschrift für Wirtschafts-und Unternehmensethik, 5(3), 228-241.

Gervautz, M., \& Schmalstieg, D. (2012). Anywhere interfaces using handheld augmented reality. Computer, 45(7), 26-31.

Gordon, R., Butler, K. A., Magee, C. A., Waitt, G. R., \& Cooper, P. (2015). World Social Marketing Conference Proceedings Book. Sydney: Fuse Events.

Hall, J. K., \& Martin, M. J. (2005). Disruptive technologies, stakeholders and the innovation value-added chain: a framework for evaluating radical technology development. $R \& D$ Management, 35(3), 273-284.

Hall, T., \& Bannon, L. (2006). Designing ubiquitous computing to enhance children's learning in museums. Journal of Computer Assisted Learning, 22(4), 231-243.

Han, D. I., tom Dieck, M. C., \& Jung, T. (2017). User experience model for augmented reality applications in urban heritage tourism. Journal of Heritage Tourism, 1-16.

Jiang, Y., \& Kim, Y. (2015). Developing multi-dimensional green value: extending social exchange theory to explore customers' purchase intention in green hotels-evidence from Korea. International Journal of Contemporary Hospitality Management, 27(2): 308-334.

Jung, S., Kim, S. \& Kim, S. (2013). Augmented reality-based exhibit information personalized service architecture through spectator's context analysis. International Journal of Multimedia and Ubiquitous Engineering, 8(4), 313-320.

Jung, T., Chung, N. \& Leue, M.C. (2015a). The determinants of recommendations to use augmented reality technologies: The case of a Korean theme park. Tourism Management 49, 75-86.

Jung, T., tom Dieck, M.C., Lee, H. \& Chung, N. (2015b). The moderating effect of long-term orientation on experience economy in augmented reality adoption. Paper presented at EuroCHRIE conference, 15-17 October 2015, Manchester.

Kamal, M., Weerakkody, V., \& Irani, Z. (2011). Analyzing the role of stakeholders in the adoption of technology integration solutions in UK local government: An exploratory study. Government Information Quarterly, 28(2), 200-210. 
Kelly, L. (2006). Measuring the impact of museums on their communities: The role of the 21st century museum. Proceedings of INTERCOMM 2006.

Koller, M., Floh, A., \& Zauner, A. (2011). Further insights into perceived value and consumer loyalty: a 'green' perspective. Psychology \& Marketing, 28(12), 1154-1176.

Kourtit, K., Macharis, C., \& Nijkamp, P. (2014). Planning for Urban Historical-Cultural Heritage: A Geo-Imaging Multicriteria Approach. Built Environment, 40(4), 521-533.

Lee, O., Uslay, C., \& Meuter, M. (2013). Antecedents and consequences of technology orientation for small firms. In N. Ndubisi, and S. Nwankwo (Eds.), Enterprise development in SMEs and entrepreneurial forms: dynamic processes (pp. 214-238), Hershey: Business Science Reference.

Leue, M., Jung, T. \& tom Dieck, D. (2015). Google Glass augmented reality: generic learning outcomes for art galleries. In I. Tussyadiah, \& A. Invesini (Eds.), Information and communication technologies in tourism 2015 (pp. 463-476), Heidelberg: Springer.

Li, Q. (2007). Student and teacher views about technology: A tale of two cities?. Journal of research on Technology in Education, 39(4), 377-397.

Linaza, M. T., Gutierrez, A. \& García, A. (2013). Pervasive augmented reality games to experience tourism destinations. In L. Cantoni, and Z. Xiang (Eds.), Information and communication technologies in tourism 2014 (pp. 497-509), Heidelberg: Springer.

Lindqvist, K. (2012). Museum finances: challenges beyond economic crises. Museum Management and Curatorship, 27(1), 1-15.

Marimon, D., Sarasua, C., Carrasco, P., Alvarez, R., et al. (2010). MobiAR: tourist experiences through mobile augmented reality. Telefonica Research and Development, Barcelona, Spain.

Mayers, J. (2005). Stakeholder power analysis. International Institute for Environment and Development. Retrieved 5.07.15. from: http://www.policypowertools.org/Tools/Understanding/docs/stakeholder_power_tool_english.pdf.

McCabe, S., Sharples, M., \& Foster, C. (2012). Stakeholder engagement in the design of scenarios of technology-enhanced tourism services. Tourism Management Perspectives, $4,36-44$.

McDougall, G. H., \& Levesque, T. (2000). Customer satisfaction with services: putting perceived value into the equation. Journal of services marketing, 14(5), 392-410.

Melville, N., Kraemer, K., \& Gurbaxani, V. (2004). Information technology and organization performance: an integrative model of business value. MIS Quarterly, 28(4), 283-322.

Mintzberg, H. (1983). Power in and around organizations. Englewood Cliffs: Prentice- Hall

Mitchell, R.K., Agle, B.R., \& Wood, D.J. (1997). Toward a theory of stakeholder identification and salience: defining the principle of who and what really counts. The Academy of Management Review, 22(4), 853-886.

Moorhouse, N., tom Dieck, M. C., \& Jung, T. (2017). Augmented Reality to enhance the Learning Experience in Cultural Heritage Tourism: An Experiential Learning Cycle Perspective. eReview of Tourism Research, 8, 1-5.

Nickols, F. W. (2005). Why a stakeholder approach to evaluating training. Advances in Developing Human Resources, 7(1), 121-134.

Noh, Z., Shahrizal M. \& Pan, Z. (2009). A review on augmented reality for virtual heritage system. In M. Chang, R. Kuo, Kinshuk, G. Chen \& M. Hirose (Eds). Learning by playing. game-based education system design and development (pp. 50-61), Heidelberg: Springer.

Peppard, J., \& Ward, J. (2016). The strategic management of information systems: building a digital strategy. Chichester: John Wiley \& Sons.

Prayag, G., \& Ryan, C. (2011). The relationship between the 'push'and 'pull'factors of a tourist destination: The role of nationality-an analytical qualitative research approach. Current Issues in Tourism, 14(2), 121-143. 
Rauschnabel, P. A., Brem, A., \& Ivens, B. S. (2015). Who will buy smart glasses? Empirical results of two pre-market-entry studies on the role of personality in individual awareness and intended adoption of Google Glass wearables. Computers in Human Behavior, 49, 635-647.

Rauschnabel, P. A., \& Ro, Y. K. (2016). Augmented reality smart glasses: An investigation of technology acceptance drivers. International Journal of Technology Marketing, 11(2), 123-148.

Sánchez-Fernández, R., \& Iniesta-Bonillo, M. Á. (2007). The concept of perceived value: a systematic review of the research. Marketing theory, 7(4), 427-451.

Sautter, E.T., \& Leisen, B. (1999). Managing stakeholders - a tourism planning model. Annals of Tourism Research, 26(2), 312-328.

Taebi, B., Correlje, A., Cuppen, E., Dignum, M., \& Pesch, U. (2014). Responsible innovation as an endorsement of public values: The need for interdisciplinary research. Journal of Responsible Innovation, 1(1), 118-124.

Tipping, J. W., Zeffren, E., \& Fusfeld, A. R. (1995). Assessing the value of your technology. Research Technology Management, 38(5), 22-39.

tom Dieck, M. C., Jung, T., \& Han, D. I. (2016). Mapping requirements for the wearable smart glasses augmented reality museum application. Journal of Hospitality and Tourism Technology, 7(3), 230-253.

tom Dieck, M.C. \& Jung, T. (2015). A theoretical model of mobile augmented reality acceptance in urban heritage tourism. Current Issues in Tourism, 18, 1-21.

van Krevelen, D. W. F. \& Poelman, R. (2010). A survey of augmented reality technologies, applications and limitations. International Journal of Virtual Reality, 9(2), 1-20.

Vogt, C., Jordan, E., Grewe, N., \& Kruger, L. (2016). Collaborative tourism planning and subjective well-being in a small island destination. Journal of Destination Marketing \& Management, 5, 36-43.

vom Lehn, D., \& Heath, C. (2005). Accounting for new technology in museum exhibitions. International Journal of Arts Management, 11-21.

Wang, X., Kim, M. J., Love, P. E. \& Kang, S. C. (2013). Augmented reality in built environment: classification and implications for future research. Automation in Construction, 32, 1-13.

Ward, J., \& Daniel, E. (2006). Benefits management: Delivering value from IS \& IT investments. Chichester: John Wiley \& Sons.

Wu, C. H. J., \& Liang, R. D. (2009). Effect of experiential value on customer satisfaction with service encounters in luxury-hotel restaurants. International Journal of Hospitality Management, 28(4), 586-593.

Yoon, S. A., Elinich, K., Wang, J., Steinmeier, C., \& Tucker, S. (2012). Using augmented reality and knowledge-building scaffolds to improve learning in a science museum. International Journal of Computer-Supported Collaborative Learning, 7(4), 519-541.

Yovcheva, Z., Buhalis, D. \& Gatzidis, C. (2012). Overview of smartphone augmented reality applications for tourism. e-Review of Tourism Research, 10(2), 1-5.

Yuan, Y. H., \& Wu, C. K. (2008). Relationships among experiential marketing, experiential value, and customer satisfaction. Journal of Hospitality \& Tourism Research, 32(3), 387410.

Yuksel, F., Bramwell, B., \& Yuksel, A. (1999). Stakeholder interviews and tourism planning at Pamukkale, Turkey. Tourism Management, 20(3), 351-360. 